\title{
37. PERIODIC COMET TEMPEL-TUTTLE AND THE LEONID METEOR SHOWER
}

\author{
E. D. KONDRAT'EVA \\ Kazan University, Kazan, U.S.S.R.
}

\begin{abstract}
P/Tempel-Tuttle, the comet associated with the Leonid meteor shower, was observed at only two of its last four passages through perihelion, in 1865-1866 and 1965 . We have re-reduced the observations in 1865-1866, and with the help of Belyaev's computer programme for numerical integration have linked the two apparitions.
\end{abstract}

Periodic comet Tempel-Tuttle was discovered on 1865 December 21 and observed up to 1866 February 9 . It was a diffuse object of magnitude 12 with a central condensation of diameter $5^{\prime}$. During this interval 118 observations were made, almost the same number before perihelion as after. Oppolzer (1866) computed an orbit but pointed out that the period of revolution obtained was not very certain. Using that orbit Bidschof (1897) calculated a search ephemeris for the comet's 1899 return. The comet was not found then, and neither was it found in 1932. Kanda (1932) calculated the orbit of the comet of 1366, using observations on October 25, 26 and 29, and he suggested that this comet was identical with $\mathrm{P} /$ Tempel-Tuttle. Schubart (1965) integrated the equations of motion of $\mathrm{P} / \mathrm{Tempel}$-Tuttle, making allowance for the perturbations by the outer planets, and assuming various values for the period. The calculations were made for 15 revolutions, back from 1866 to 1366. Despite the inaccuracy of the ancient observations, but with the help of what appeared to be a single observation of the comet in 1699 , he could choose an appropriate value for the period of revolution and derive a prediction for 1965. He then found diffuse, sixteenth magnitude images of the comet on plates obtained on 1965 June 30 and July 1 by M. J. Bester with $25-\mathrm{cm}$ astrograph of the Boyden Observatory. Only four observations were obtained at this apparition, and they agree well with Schubart's prediction, provided that the latter is corrected by $\Delta T=+5$ days.

We have improved Schubart's elements by means of the observations in 1965. After applying the $\Delta T$ correction we corrected the elements three times by the EckertBrouwer method, with the result:

$$
\left.\begin{array}{rl}
\Omega & =234^{\circ} 32^{\prime} 49^{\prime \prime} 85 \\
\omega & =1725809.21 \\
i & =1624328.33
\end{array}\right\} \quad 1950.0
$$

and the $(\mathrm{O}-\mathrm{C})$ residuals: 


$\begin{array}{lrll}1965 & & \Delta \alpha \cos \delta & \Delta \delta \\ \text { June } & 30.1 & -0.03 & +0.15 \\ & 30.5 & +0.22 & +1.01 \\ \text { July } & 1.1 & -0.16 & -4.73 \\ & 26.5 & +0.13 & +0.13 .\end{array}$

We then integrated these elements back to 1866 , using the computer programme kindly supplied by Belyaev, which takes into account the perturbations by Venus to Pluto. The result was:

$$
\left.\begin{array}{rlr}
\text { Epoch } & =1866 \text { February } 8.0 \mathrm{UT} \\
M_{0} & =0^{\circ} 36^{\prime} 54^{\prime \prime} .31 \\
\Omega & =232^{\circ} 39^{\prime} 02.27 \\
\omega & =171 \quad 1624.78 \\
i & =1624226.60
\end{array}\right\} \quad 1950.0
$$

The 118 observations of 1865-1866 have been re-reduced, the positions of the reference stars being taken from the Yale zone catalogues or $\mathrm{AGK}_{2}$ and corrected to the $\mathrm{FK}_{4}$ system. Oppolzer's seven normal places were then adjusted, and the following elements were obtained by differential correction of the above elements:

$$
\left.\begin{array}{rl}
\text { Epoch } & =1866 \text { January } 11.0 \mathrm{UT} \\
M_{0} & =-0^{\circ} 01^{\prime} 06^{\prime \prime} 68718 \\
\Omega & =232^{\circ} 34^{\prime} 58.50 \\
\omega & =1705556.28 \\
i & =16241 \quad 13.51
\end{array}\right\} \quad 1950.0
$$

these elements represent the normal places as follows:

$\begin{array}{llll}\text { 1865/66 } & \Delta \alpha \cos \delta & \Delta \delta \\ \text { Dec. } 22.0 & +0.61 & +4.07 \\ & 27.5 & +0.38 & +4.72 \\ \text { Jan. } & 4.5 & -1.24 & -2.63 \\ & 9.5 & -1.12 & -0.31 \\ & 15.5 & -0.57 & -6.72 \\ & 22.5 & -1.14 & -4.14 \\ \text { Feb. } & 5.5 & +0.35 & +1.47\end{array}$

The new elements were then reintegrated from 1866 to 1965 . It was necessary to 
make a further correction to the mean anomaly, and a final differential correction gave the result:

$$
\left.\begin{array}{rl}
\text { Epoch } & =1866 \text { January } 11.0 \mathrm{UT} \\
M_{0} & =-67^{\prime \prime} .55842 \\
\Omega & =232^{\circ} 34^{\prime} 38^{\prime \prime} .13 \\
\omega & =1705618.65 \\
i & =1624148.33
\end{array}\right\} \quad 1950.0
$$

1965 April 30.0 UT

-10 ".38647

$234^{\circ} 33^{\prime} 07^{\prime \prime} .19$

1725909.19

1624340.33

10.259808

0.9039863 .

The final residuals are:

\begin{tabular}{lrll} 
1865/66 & $\Delta \alpha \cos \delta$ & \multicolumn{1}{c}{$\Delta \delta$} \\
Dec. & 22.0 & -0.13 & +0.38 \\
& 27.5 & +0.70 & -1.25 \\
Jan. & 4.5 & -0.10 & +3.08 \\
& 9.5 & +0.11 & +2.46 \\
& 15.5 & +0.12 & -3.51 \\
& 22.5 & -0.12 & -3.09 \\
Feb. & 5.5 & +0.16 & -6.55 \\
1965 & & & \\
June & 30.1 & -0.30 & +3.45 \\
& 30.5 & -0.29 & +3.99 \\
July & 1.1 & +0.63 & -0.70 \\
& 26.5 & +0.08 & +0.07.
\end{tabular}

From the exact orbital elements of P/Tempel-Tuttle we can determine by Dubyago's method the circumstances of the Earth's interception of the Leonid meteor stream. For 1966 the time of maximum was calculated to be November $17^{\mathrm{d}} 10^{\mathrm{h}} 42^{\mathrm{m}} \mathrm{UT}$, which is in good agreement with the observations.

\section{References}

Bidschof, F.: 1897, Astron. Nachr. 144, 299.

Kanda, S.: 1932, Astron. Herald 25, 187.

Oppolzer, T.: 1866, Astron. Nachr. 68, 241.

Schubart, J.: 1965, IAU Circ. No. 1907. 